\title{
ANALISIS RENTABILITAS DAN PROFITABILITAS PADA KOPERASI SIMPAN PINJAM BALO' TORAJA KSP. BALO'TA
}

\author{
Imran Ukkas ${ }^{1}$ \\ Wirda Ayu Ningsi²
}

No. HP $081343665845^{1}$

\begin{abstract}
ABSTRAK
Tujuan penelitian adalah untuk mengetahui dan menganalisa tingkat rentabilitas dan profitabilitas Koperasi Simpan Pinjam Balo' Toraja tahun 2011-2013. Metode analisis data yang dipergunakan dalam penelitian ini adalah Analisis Rasio, dimana rasio rentabilitas terdiri dari rentabilitas ekonomi dan rentabilitas modal sendiri. Sedangkan untuk rasio profitabilitas yaitu gross profit margin, operating profit margin, net profit margin. Hasil penelitian dengan menggunakan analisis rasio rentabilitas menunjukkan bahwa pada rasio rentabilitas ekonomi mengalami penurunan setiap tahunnya dan pada rasio rentabilitas modal sendiri mengalami peningkatan setiap tahunnya. Sedangkan hasil penelitian dengan menggunakan analisis rasio rentabilitas menunjukkan bahwa pada gross profit margin mengalami penurunan setiap tahunnya, pada operating profit margin mengalami naik turun (berfluktuasi) setiap tahunnya, dan pada net profit margin mengalami peningkatan setiap tahunnya.
\end{abstract}

\section{Kata Kunci: Rentabilitas Ekonomi,Rentabili tas Modal Sendiri, Gross Profit Margin, Operating Profit Margin, dan Net Profit Margin.}

\section{PENDAHULUAN}

Memasuki milenium ketiga, pada saat persaingan dunia usaha semakin mengglobal, sebagai salah satu pelaku ekonomi koperasi yang mempunyai kedudukan sebagai soko guru perekonomian nasional dan sebagai bagian integral tata perekonomian nasional (Penjelasan pasal 33 UUD 1945) harus memiliki daya saing yang berkelanjutan. Faktor utama yang mendapat perhatian adalah faktor rentabilitas dan profitabilitas, karena rentabilitas dan profitabilitas dapat digunakan untuk mengukur kesuksesan perusahaan/koperasi dan kemampuan menggunakan kekayaan atau modal secara produktif.

Ukuran yang seringkali dipakai untuk menilai berhasil atau tidaknya suatu perusahaan adalah laba yang diperoleh perusahaan (Mulyadi, 2001:225). Akan tetapi laba yang besar belum cukup sebagai ukuran keberhasilan koperasi/perusahaan bekerja dengan efisien. Efisien baru dapat dikstahui dengan membandingkan laba yang oleh dengan kekayaan atau modal yang menghasilkan laba tersebut. Dengan demikian yang perlu diperhatikan oleh koperasi tidak hanya memperbesar laba, tetapi yang lebih penting adalah usaha untuk 
mempertinggi rentabilitas dan profitabilitasnya. Oleh karena itu koperasi lebih diarahkan untuk mempertinggi tingkat rentabilitas maksimal dan profitabilitas maksimal.

Dengan rentabilitas dan profitabilitas maka dapat diketahui kemampuan koperasi untuk menghasilkan laba selama periode tertentu. Koperasi Simpan Pinjam Balo' Toraja merupakan koperasi yang beranggotakan masyarakat umum.

\section{METODE PENELITIAN}

Penelitian ini akan dilaksanakan pada empat Penelitian ini, mengambil lokasi penelitian pada Koperasi Simpan Pinjam Balo' Toraja (KSP. Balo'ta) yang terletak di Jln. RA. Kartini No. 7 Kecamatan Makale, Kabupaten Tana Toraja, Provinsi Sulawesi Selatan.jenis data yang digunakan adalah primer dan sekunder. Metode yang digunakan dalam penelitian ini yaitu wawancara dan dokumentasi. Sedangakn Metode analisis datanya digunakan untuk mengelola data yang telah terkumpul untuk kemudian dapat memberikan interprestasi dalam pengelolaan data dan digunakan untuk menjawab masalah yang telah dirumuskan. Dalam penelitian ini menggunakan analisis kuantitatif dan analisis kualitatif. Analisis kuantitatif berupa angkaangka hasil perhitungan atau pengukuran yang diproses untuk dapat memperoleh presentase yang diklasifikasikan untuk memperoleh data. Data tersebut kemudian dikualitatifkan dengan cara menggambarkan dengan kata-kata atau kalimat yang dipisah- pisahkan menurut kategori untuk memperoleh kesimpulan.

Pada analisis ini dilakukan dengan menganalisa gambaran mengenai Neraca dan Laporan perhitungan laba atau rugi pada Koperasi Simpan Pinjam Balo' Toraja selama 3 tahun yaitu tahun 2011-2013 (Arikunto,1997:245). Teknik analisis data yang digunakan adalah:

1. Analisis Rasio

Analisis rasio ini digunakan untuk mengetahui tingkat rentabilitas dan profitabilitas pada KSP. Balo'ta.

Rasio - rasio yang digunakan antara lain:
a. Rasio Rentabilitas Ekonomi
b. Rasio Rentabilitas Modal Sendiri
c. Gross Profit Margin
d. Operating Profit margin
e. Net Profit Margin

2. Analisis Trend

Analisis trend digunakan untuk mengetahui tendensi dari keadaan keuangan, apakah menunjukkan tendensi tetap, naik, atau turun. Tren dalam persentase dihitung dengan memilih tahun pertama sebagai tahun dasarnya.

\section{HASIL DAN PEMBAHASAN}

Berikut ini adalah laporan keuangan dari Koperasi Simpan Pinjam Balo' Toraja (KSP. Balo'ta), yang dibutuhkan dalam melakukan analisis rasio rentabilitas berdasarkan analisis kinerja keuangannya. 
Tabel 1

HASIL UJI CONVERGENT VALIDITY OUTER LOADING(REFLEKTIF)

\begin{tabular}{|c|c|c|c|}
\hline \multicolumn{4}{|c|}{ KOPERASI SIMPAN PINJAM BALO' TORAJA(KSP. BALO'TA) } \\
\hline \multicolumn{4}{|c|}{ NERACA PER 31 DESEMBER 2011-2013 } \\
\hline \multicolumn{4}{|c|}{ (DALAM RUPIAH) } \\
\hline URAIAN & 2011 & 2012 & 2013 \\
\hline SHU Sebelum Beban Perkoperasian & $6,035,092,453$ & $6,710,827,160$ & $7,106,959,326$ \\
\hline SHU Setelah Pajak & $281,616,042$ & $759,792,577$ & $1,159,481,715$ \\
\hline Total Modal Sendiri & $66,565,035,709$ & $77,970,590,523$ & $89,261,607,360$ \\
\hline Total Asset & $181,927,359,340$ & $209,607,074,303$ & $238,955,011,444$ \\
\hline
\end{tabular}

1. Rasio Rentabilitas

Dalam hal ini alat ukur yang di gunakan untuk menilai tingkat rentabilitas pada Koperasi Simpan Pinjam Balo' Toraja adalah:

a. Rentabilitas Ekonomi

Berdasarkan data laporan keuangan neraca tahun 2011, 2012, dan 2013 pada lampiran 1 menunjukkan bahwa kondisi riil rentabilitas ekonomi KSP. Balo'ta adalah sebagai berikut:

SHU Sebelum Beban

Perkoperasian

Rentabilitas Ekonomi $=\overline{\text { Total Asset }} \times 100 \%$

6.035.092.459

Rentabilitas Ekonomi $=\longrightarrow \times 100 \%$

(2011) 181.927.359.340

$$
=3,32 \%
$$

6.710 .827 .160

Rentabilitas Ekonomi $=-\times 100 \%$ (2012)

209.607.074.303

$$
=3,20 \%
$$

7.106.959.326

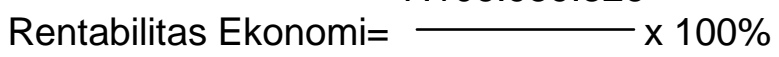
(2013) 238.955.011.444

$$
=2,97 \%
$$

Pada tahun 2011 setiap total asset $100 \%$ mampu memperoleh SHU sebelum beban perkoperasian sebesar 3,32\%. Pada tahun 2012 setiap total asset 100\% mampu memperoleh SHU sebelum beban perkoperasian sebesar 3,20\%. Dan pada tahun 2013 setiap total asset $100 \%$ mampu memperoleh SHU sebelum beban perkoperasian sebesar $2,97 \%$. 
Berdasarkan

hasil

perhitungan di atas rentabilitas ekonomi Koperasi Simpan Pinjam balo' Toraja (KSP. Balo'ta) mengalami penurunan setiap tahunnya. Hal tersebut disebabkan karena Total Asset mengalami peningkatan lebih besar dibanding SHU sebelum beban perkoperasian. Artinya bahwa terdapat total asset tidak produktif atau menganggur, yang menyebabkan SHU sebelum beban perkoperasian turun dari tahun ke tahun.

b. Rentabilitas Modal Sendiri SHU Setelah Pajak

$\begin{gathered}\text { Rentabilitas Modal } \\ \text { Sendiri }\end{gathered}=\frac{}{\text { Modal Sendiri }} \times 100 \%$ $\begin{aligned} \begin{aligned} \text { Rentabilitas Moda } \\ \text { Sendiri (2011) }\end{aligned} & \frac{281.616 .042}{66.565 .745 .789} \times 100 \% \\ & =0,42 \% \\ & 759.792 .576\end{aligned}$ Rentabilitas Modal $=1 \times 100 \%$ Sendiri (2012) $\quad 77.970 .590 .523$ $=0,97 \%$

$$
\begin{aligned}
\begin{aligned}
\text { Rentabilitas Modal } \\
\text { Sendiri (2013) }
\end{aligned} & \frac{1.159 \cdot 481.715}{89.261 .607 .360} \times 100 \% \\
& =1,30 \%
\end{aligned}
$$

Pada tahun 2011 setiap modal sendiri $100 \%$ mampu memperoleh SHU sebelum pajak sebesar 0,42\%. Pada tahun 2012 setiap modal sendiri $100 \%$ mampu memperoleh SHU sebelum pajak sebesar 0,97\%. Dan pada tahun 2013 setiap modal sendiri 100\% mampu memperoleh SHU sebelum pajak sebesar $1,30 \%$.

Berdasarkan hasil perhitungan rentabilitas modal sendiri pada Koperasi Simpan Pinjam balo' Toraja (KSP. Balo'ta) mengalami peningkatan setiap tahunnya. Hal tersebut disebabkan karena Modal Sendiri mengalami peningkatan lebih besar dibanding SHU setelah pajak. Artinya bahwa modal sendiri produktif dalam operasional, sehingga mendorong atau meningkatkan SHU setelah pajak pada Koperasi Simpan pinjam balo' Toraja (KSP. Balo'ta).

Tabel 2: Hasil Perhitungan Nilai Rentabilitas Tahun 2011, 2012, dan 2013

\begin{tabular}{|l|l|l|l|}
\hline \multicolumn{1}{|c|}{$\begin{array}{l}\text { Tahun } \\
\text { Rasio }\end{array}$} & 2011 & 2012 & 2013 \\
\hline $\begin{array}{l}\text { Rentabilitas } \\
\text { Ekonomi }\end{array}$ & $3,32 \%$ & $3,20 \%$ & $2,97 \%$ \\
\hline $\begin{array}{l}\text { Rentabilitas } \\
\text { Modal } \\
\text { Sendiri }\end{array}$ & $0,42 \%$ & $0,97 \%$ & $1,30 \%$ \\
\hline
\end{tabular}

Sumber : Data tabel 1 diolah 
Tabel 3

\begin{tabular}{|c|c|c|c|}
\hline \multirow{3}{*}{\multicolumn{4}{|c|}{$\begin{array}{l}\text { KOPERASI SIMPAN PINJAM BALO' TORAJA (KSP. BALO'TA) } \\
\text { PERHITUNGAN SISA HASIL USAHA (PHU) PER } 31 \text { DESEMBER 2011-2013 } \\
\text { (DALAM RUPIAH) }\end{array}$}} \\
\hline & & & \\
\hline & & & \\
\hline URAIAN & 2011 & 2012 & 2013 \\
\hline Pendapatan & $33,238,244,648$ & $36,410,275,067$ & $41,150,196,198$ \\
\hline Beban Pokok & $13,234,360,849$ & $15,004,782,412$ & $17,015,518,370$ \\
\hline Pendapatan Kotor & $20,003,883,799$ & $21,405,492,655$ & $24,134,677,828$ \\
\hline Pendapatan Bunga & & - & - \\
\hline SHU Kotor & $20,003,883,799$ & $21,405,492,655$ & $24,134,677,828$ \\
\hline Beban Usaha & $13,968,791,346$ & $14,694,665,495$ & $17,027,718,502$ \\
\hline SHU Sebelum Beban Perkoperasian & $6,035,092,453$ & $6,710,827,160$ & $7,106,959,326$ \\
\hline Beban Perkoperasian & $5,663,761,532$ & $5,668,186,352$ & $5,560,983,706$ \\
\hline SHU Setelah Beban Perkoperasian & $371,330,921$ & $1,042,640,808$ & $1,545,975,620$ \\
\hline Pendapatan dan Beban Lain-lain & $4,157,135$ & $(29,584,039)$ & - \\
\hline SHU Sebelum Pajak & $375,488,056$ & $1,013,056,769$ & $1,545,975,620$ \\
\hline Pajak Penghasilan 25\% & $93,872,014$ & $253,264,192$ & $386,493,905$ \\
\hline SHU Setelah Pajak & $281,616,042$ & $759,792,577$ & $1,159,481,715$ \\
\hline
\end{tabular}

2. Rasio Profitabilitas

a. Gross Profit Margin

\begin{aligned} & Gross Profit Margin $=\frac{\text { Pendapatan }- \text { Beban Pokok }}{\text { Pendapatan }} \times 100 \% \\ &$ Gross Profit Margin (2011) $=\frac{33.238 .244 .648-13.234 .360 .849}{33.238 .244 .648} \times 100 \% \\ &=60,18 \% \\ &$ Gross Profit Margin (2012) $=\frac{36.410 .275 .067-15.004 .782 .412}{36.410 .275 .067} \times 100 \% \\ &=58,79 \% \\ &$\hline Gross Profit Margin (2013) $=\frac{41.150 .196 .198-17.015 .518 .370}{41.150 .196 .198} \\ &=58,65 \% \\ &\end{aligned}$


Pada tahun 2011 setiap

pendapatan $\quad 100 \% \quad$ mampu memperoleh beban pokok sebesar 60,18\%. Pada tahun 2012 setiap pendapatan $\quad 100 \% \quad$ mampu memperoleh beban pokok sebesar 58,79\%. Dan pada tahun 2013 setiap pendapatan $\quad 100 \%$ mampu memperoleh beban pokok sebesar $58,65 \%$.
Berdasarkan

hasil perhitungan Gross Profit Margin pada Koperasi Simpan Pinjam balo' Toraja (KSP. Balo'ta) mengalami penurunan setiap tahunnya. Hal tersebut disebabkan karena Beban Pokok mengalami peningkatan lebih besar dibanding Pendapatan. Artinya bahwa terdapat atau terjadi pemberosan atau in efisien dalam biaya operasional.

b. Operating Profit Margin

\begin{tabular}{|c|c|c|c|}
\hline \multirow{2}{*}{ Operating Profit Margin = } & \multicolumn{2}{|c|}{ SHU Sebelum Beban Perkoperasian } & \multirow{2}{*}{$x 100 \%$} \\
\hline & \multicolumn{2}{|l|}{ Pendapatan } & \\
\hline \multirow{3}{*}{ Operating Profit Margin (2011) $=$} & 6.035 .092 .453 & \multirow{3}{*}{$x 100 \%$} & \\
\hline & 33.238 .244 .648 & & \\
\hline & $18,16 \%$ & & \\
\hline \multirow{3}{*}{ Operating Profit Margin (2012) = } & 6.710 .827 .160 & \multirow{3}{*}{ x 100\% } & \\
\hline & 36.410 .275 .067 & & \\
\hline & $18,43 \%$ & & \\
\hline \multirow{3}{*}{ Operating Profit Margin (2013) = } & 7.106.959.326 & \multirow{3}{*}{$x 100 \%$} & \\
\hline & 41.150.196.198 & & \\
\hline & $17,27 \%$ & & \\
\hline
\end{tabular}


Pada tahun 2011 setiap

pendapatan $\quad 100 \% \quad$ mampu memperoleh SHU seblum beban perkoperasian sebesar $18,16 \%$. Pada tahun 2012 setiap pendapatan $100 \%$ mampu memperoleh SHU sebelum beban perkoperasian sebesar 18,43\%. Dan pada tahun 2013 setiap pendapatan 100\% mampu memperoleh SHU sebelum beban perkoperasian sebesar $17,27 \%$.

Berdasarkan hasil perhitungan Operating Profit Margin pada Koperasi Simpan Pinjam balo' Toraja (KSP. Balo'ta) mengalami naik turun setiap tahunnya.
Pada tahun 2012 mengalami peningkatan disebabkan karena pendapatan lebih besar dibandingkan SHU sebelum beban perkoperasian. Sedangkan, pada tahun 2013 mengalami penurunan karena SHU sebelum beban perkoperasian lebih besar dibanding pendapatan. Artinya bahwa karyawan KSP.Balo'ta kurang disiplin dalam menetapkan biaya-biaya usaha setiap tahun, sehingga SHU sebelum beban perkoperasan KSP. Balo'ta berfluktuasi setiap tahunnya.

c. Net Profit Margin

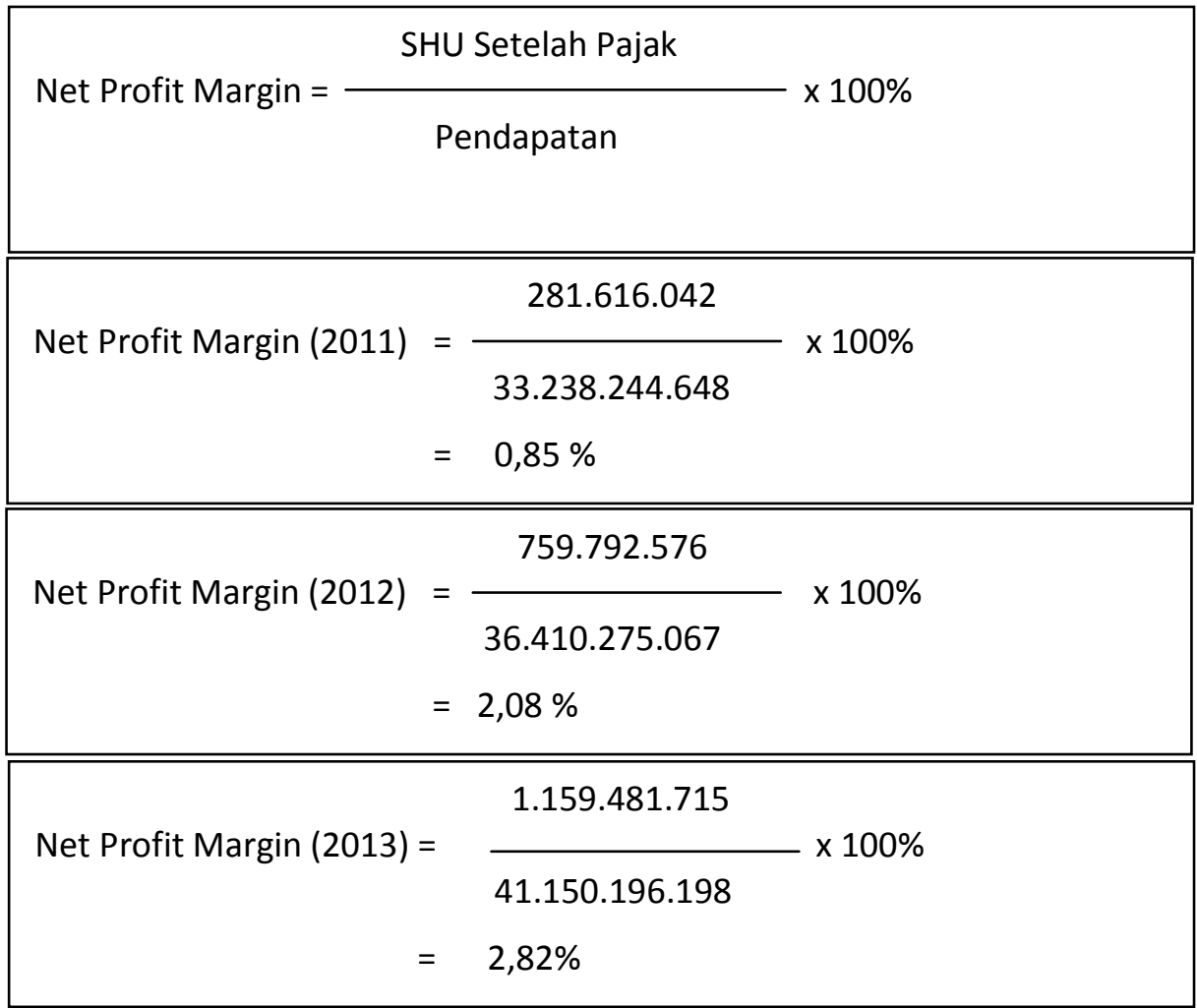


Pada tahun 2011 setiap pendapatan $\quad 100 \% \quad$ mampu memperoleh SHU setelah pajak sebesar 0,85\%. Pada tahun 2012 setiap pendapatan 100\% mampu memperoleh SHU setelah pajak sebesar 2,09\%. Dan pada tahun 2013 setiap pendapatan $100 \%$ mapu memperoleh SHU setelah pajak sebesar $2,82 \%$.

Berdasarkan hasil perhitungan Net Profit Margin pada Koperasi Simpan Pinjam balo' Toraja (KSP. Balo'ta) mengalami peningkatan setiap tahunnya.
Hal tersebut disebabkan karena SHU setelah pajak mengalami peningkatan lebih besar disbanding pendapatan. Artinya bahwa Manajer Koperasi Simpan Pinjam Balo' Toraja (KSP. Balo'ta) berhasil dalam menetapkan biaya terutama biaya bunga dan pajak penghasilan.

Tabel 4: Hasil Perhitungan Nilai Profitabilitas Tahun 2011-2013.

\begin{tabular}{|l|c|c|c|}
\hline Rasio & 2011 & 2012 & 2013 \\
\hline Gross Profit Margin & $60,18 \%$ & $58,79 \%$ & $58,65 \%$ \\
\hline Operating Profit Margin & $18,16 \%$ & $18,43 \%$ & $17,27 \%$ \\
\hline Net Profit Margin & $0,85 \%$ & $2,09 \%$ & $2,82 \%$ \\
\hline
\end{tabular}

\section{SIMPULAN}

Berdasarkan uraian - uraian pada hasil penelitian dan pembahasan maka peneliti dapat menarik kesimpulan sebagai berikut:

1. Dari hasil analisis kinerja keuangan pada Koperasi Simpan Pinjam Balo' Toraja (KSP. Balo'ta) dengan menggunakan penilaian Rasio Rentabilitas posisi rentabilitasnya yang ditunjukkan oleh rentabilitas ekonomi mengalami penurunan dan Rentabilitas Modal Sendiri mengalami Peningkatan.
2. Rentabilitas ekonomi pada Koperasi Simpan Pinjam balo' Toraja (KSP. Balo'ta) mengalami penurunan setiap tahunnya. Hal tersebut disebabkan karena terdapat total asset tidak produktif atau menganggur, yang menyebabkan SHU sebelum beban perkoperasian turun dari tahun ke tahun. Sedangkan, rentabilitas modal sendiri pada Koperasi Simpan Pinjam balo' Toraja (KSP. Balo'ta) mengalami peningkatan setiap tahunnya. Hal tersebut disebabkan karena modal sendiri produktif dalam operasional, sehingga mendorong atau meningkatkan 
SHU setelah pajak pada Koperasi Simpan pinjam balo' Toraja (KSP. Balo'ta).

3. Dari hasil analisis kinerja keuangan pada Koperasi Simpan Pinjam Balo' Toraja (KSP. Balo'ta) dengan menggunakan penilaian Rasio Profitabilitas posisi profitabilitas perusahaan yang ditunjukkan oleh Gross Profit Margin mengalami penurunan, Operating Profit Margin mengalami naik turun, dan Net Profit Margin mengalami peningkatan.

4. Gross Profit Margin pada Koperasi Simpan Pinjam balo' Toraja (KSP. Balo'ta) mengalami penurunan setiap tahunnya. Hal tersebut disebabkan karena terdapat atau terjadi pemberosan atau in efisien dalam biaya operasional. Operating Profit Margin pada Koperasi Simpan Pinjam balo' Toraja (KSP. Balo'ta) mengalami naik turun setiap tahunnya. Hal tersebut disebabkan karena karyawan KSP.Balo'ta kurang disiplin dalam menetapkan biayabiaya usaha setiap tahun, sehingga SHU sebelum beban perkoperasan KSP. Balo'ta berfluktuasi setiap tahunnya. Sedangkan, Net Profit Margin pada Koperasi Simpan Pinjam balo' Toraja (KSP. Balo'ta) mengalami peningkatan setiap tahunnya. Hal tersebut disebabkan karena Manajer Koperasi Simpan Pinjam Balo' Toraja (KSP. Balo'ta) berhasil dalam menetapkan biaya terutama biaya bunga dan pajak penghasilan.

5. Dari kedua rasio untuk mengukur kinerja keuangan pada Koperasi Simpan Pinjam Balo' Toraja (KSP. Balo'ta) yaitu Rasio
Rentabilitas dan Rasio Profitabilitas sudah membuktikan hipotesis penelitian.

\section{SARAN}

Berdasarkan hasil pembahasan dan kesimpulan yang diperoleh dalam penelitian ini, maka dapat diberikan saran sebagai berikut:

1. Koperasi Simpan Pinjam Balo' Toraja (KSP. Balo'ta) hendaknya terus memperhatikan Total Asset agar produktif (tidak menganggur). Karena jika tidak memperhatikan total asset dapat menyebabkan SHU sebelum beban perkoperasian turun dari tahun ke tahun dan tidak menutup kemungkinan perusahaan akan mengalami kesulitan dalam memenuhi kewajiban-kewajibannya.

2. Koperasi Simpan Pinjam Balo' Toraja (KSP. Balo'ta) harus berusaha untuk meningkatkan pendapatan, dimana pendapatan harus lebih besar dibanding beban pokok karena tedapat pemberosan in efisien dalam biaya operasional.

3. Karyawan Koperasi Simpan Pinjam Balo' Toraja (KSP. Balo'ta) harus lebih disiplin dalam menetapkan biaya-biaya usaha setiap tahun, sehingga SHU sebelum beban perkoperasian yang di peroleh Koperasi Simpan Pinjam Balo' Toraja (KSP. Balo'ta) tidak berfluktuasi setiap tahunnya.

Bagi peneliti selanjutnya yang ingin meneliti dengan topik yang sama dengan penelitian ini hendaknya menambahkan kriteria rasio penilaian seperti Rasio Aktivitas, yang 
nantinya dapat memberikan informasi yang lebih akurat lagi untuk pengukuran kinerja keuangan.

\section{DAFTAR PUSTAKA}

Djarwanto. 1993. Pokok - pokok Analisa Laporan Keuangan. Yogyakarta: BPFE.

S. Munawir. 1992. Analisa Laporan Keuangan. Cetakan Tujuh. Yogyakarta: Penerbit LIBERTY.

Sitio, Arifin dan Tamba, Halomoan. 2001.Koperasi Teori dan Praktek, Jakarta: Penerbit ERLANGGA. 